\title{
Research Paper: Social Anxiety Study Based on Coping Styles and Attachment Styles
}

\author{
Mohammadreza Tamannaeifar ${ }^{1 *}$, Maryam Sanatkarfar $^{1}$ \\ 1. Department of Psychology, Faculty of Humanities, University of Kashan, Kashan, Iran.
}

Citation: Tamannaeifar, M., \& Sanatkarfar, M. (2017). Social Anxiety Study Based on Coping Styles and Attachment Styles Journal of Practice in Clinical Psychology, 5(2), 115-122. https://doi.org/10.18869/acadpub.jpcp.5.2.115

doif : https://doi.org/10.18869/acadpub.jpcp.5.2.115

\section{Article info:}

Received: 08 Oct. 2016

Accepted: 15 Jan. 2017
Keywords:

Social anxiety, Coping styles, Attachment styles

\section{ABSTRACT}

Objective: The purpose of the present study was to investigate the relation of coping styles and attachment styles with social anxiety among high-school students.

Methods: The present study was correlational research. Study population comprised all male and female students of Kashan high schools. A total of 440 students (196 males and 244 females, aged from 17 to 18 years in the third or fourth grade of Kashan high schools (academic year 20152016) were selected by cluster sampling method. Data were gathered using social phobia inventory, coping inventory for stressful situation, and adult attachment inventory. For analyzing the data, analysis of regression method were used.

Results: There were significant correlations between the social anxiety problem-focused coping style $(\mathrm{r}=-0.16, \mathrm{P}<0.05)$, emotion-focused coping style $(\mathrm{r}=0.40, \mathrm{P}<0.01)$, and avoidance coping style $(\mathrm{r}=0.03, \mathrm{~N} . \mathrm{S})$. Moreover, results indicated correlations between social anxiety with secure attachment style $(\mathrm{r}=-0.10, \mathrm{P}<0.05)$, avoidant attachment style $(\mathrm{r}=0.23, \mathrm{P}<0.01)$ and ambivalent attachment style $(\mathrm{r}=0.26, \mathrm{P}<0.01)$, too. Coping styles (emotion-focused and problem-focused styles) predicted $19 \%$ variation of social anxiety and attachment styles, $11 \%$ variation of social anxiety.

Conclusion: Results of this study support the role of coping styles and attachment styles in social anxiety and show that maladaptive coping strategies predispose people to social anxiety. Also, insecure-ambivalent attachment people are vulnerable to social anxiety.

\section{Introduction}

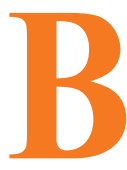

ased on the Diagnostic and Statistical Manual of Mental Disorders the fifth edition, social anxiety or social phobia is characterized by fearful or anxious feelings and avoidance of social interactions, in all of which the individual is judged by other people. For instance, people might develop social anxiety when they meet new people, are observed while eating or drinking, and perform in front of others. In other words, the individual is afraid of embarrassment, other people's evaluation, humiliation, rejection, etc. (APA, 2013). As a chronic, stable condition, social anxiety disorder (SAD) might negatively affect the patient's daily functions in the long run (Beesdo-Baum et al., 2012). The 12-month prevalence of SAD is around

* Corresponding Author:

Mohammad Reza Tamannaeifar, PhD

Address: Department of Psychology, Faculty of Humanities, University of Kashan, Kashan, Iran.

Tel: +98 (31) 55913752

E-mail: tamannai@kashanu.ac.ir 
$7 \%$ in the United States. Lower 12-month prevalence of SAD of approximately $0.5 \%-2.0 \%$ are seen in the rest of the world; median prevalence of social anxiety disorder for the Europe is $2.3 \%$. The 12 -month prevalence of SAD in children and adolescents are comparable to those in adults. Prevalence of SAD is reduced with age (APA, 2013).

Anxiety disorders and social anxiety disorder in particular, are common in childhood; they frequently turn chronic if left untreated, and are associated with emotional distress as well as impairment in social and academic functioning (Mychailyszyn et al., 2010; Alkozei, Creswell, Cooper, \& Allen, 2015). Research indicates that adolescents with social phobia manifest substantially increased risks of depression, suicide attempts, substance abuse, severe social restrictions, early school leaving, lower educational attainment, and victimization (Garcia-Lopez, Díaz-Castela, Muela-Martinez, \& Espinosa-Fernandez, 2014; Ranta, Kaltiala-Heino, Fröjd, \& Marttunen, 2012).

Fear of negative evaluation is the core feature of social anxiety and people with greater social anxiety, experience an exaggerated feeling of risk in social interactions (Afram \& Kashdan, 2015). Social anxiety is positively associated with the amount of concern experienced by the threat of rejection (Kashdan et al., 2013).

Socially anxious people tend to endorse high levels of negative cognitions, perceive ambiguous situations as threatening and report threat perception abnormalities; they underestimate their cognitive competence and social performance (Brumariu \& Kerns, 2008). Research also suggests that socially anxious people often have difficulty in identifying and regulating their emotions (Suveg \& Zeman, 2004). Students with heightened social anxiety may evaluate their relationships more negatively than students without social anxiety (Parade, Leerkes, \& Blankson, 2009), experience low levels of peer acceptance (Greco \& Morris, 2005), intimacy and support in close relationships (Brumariu \& Kerns, 2008).

Much literature on social anxiety focuses on how the fear of negative evaluation impacts the way people with social anxiety relate to unfamiliar people (Afram \& Kashdan, 2015). Considering that social anxious people evaluate social situations and interactions threatening, it is important that they cope with the stressful situations. Coping is defined as a multidimensional concept that consists of cognitive and behavioral regulatory processes to manage the internal and external requisitions during a specific stressful situation (Doron, Thomas-Ollivier, Vachon, \& Fortes-Bourbousson, 2013). It has received much attention in stress research. According to the transactional model of stress, the coping process include actions taken to manage a stressor and decrease its intensity (Lazarus \& Folkman, 1984). Various approaches have been proposed to assess the coping process. For example, Lazarus' group suggested "problem-emotion focused coping dichotomy". Later, Endler and Parker (1990) added "escape-avoidance coping" to this dichotomy. Adapting coping style consists of efforts directed to solve the stressor (active and problemfocused coping style) and maladaptive coping style include passive and emotion-focused style. They are typically less efficient in rescuing a stressful situation than adaptive coping style (Lechner, Bolman, \& van Dalen, 2006).

Coping is a key element for mental health, because the way in which people cope with stress can reduce or enhance the effects of traumatic life events (Doron et al., 2013). People who live in stress are optimistic and flexible, use effective coping strategies, have control over life events and posses/report higher mental health (Coyne, 2003). Herbert et al. (2005) found that social skills training can reduce social avoidance and distress. Liveneh, Sheldon and Kaplan (1991) reported that effective coping reduced social anxiety. Appropriate coping skills strengthens internal focus of control, promotes using problem-foused strategies, and thus reduces anxiety and fear (Lazarus \& Folkman, 1984). Thus, stress alone does not impair performance, but ineffective coping causes the problem (Faramarzi et al., 2013).

Previous research indicates that parental attachment security associates with social anxiety, which in turn is connected to relationship quality (Parade, Leerkes, \& Blankson, 2009). Attachment theory proposes that attachment quality is one factor that may impact social anxiety (Vertue, 2003). According to Bowlby (1973), children with attachment security employ the attachment figure as a safe haven from which to explore or draw back in time of distraction. Daily frequent experiences with attachment figures help children to predict the accessibility of their caregivers. Children with attachment security count on the availability and responsiveness of attachment figures. In contrast, children with attachment insecurity cannot perceive their caregivers as caring, responsive, and available. Doubt and suspicion about the accessibility of caregivers increases the eventuality to react with fear when experiencing alarming situations (Brumariu \& Kerns, 2008).

Studies indicate that securely attached people have higher levels of perceived social competence and qualified relationships with peers and friends (Bosquet \& Egeland, 2006). People with insecure attachment style experience less social anxiety (Brumariu \& Kerns, 2008). Students who have a more secure attachment to their parents, were more successful in forming friendly relations and these relations were 
more satisfied (Parade et al., 2009). People with ambivalent attachment style, said to as preoccupied people (Finnegan, Hodge, \& Perry, 1996), employ intense strategies (i.e., heightening attachment behavior such as excessive display of negative emotions) when looking for attachment figure's attention and console as a style to defeat unstable parental accessibility and intruding care (Cassidy \& Berlin, 1994). Ambivalent people have limited exploratory behavior that may prevent their adapting in social situations (Ainsworth et al., 1978; Cited in Ghassem Boroujerdi, Sohrabi, \& Borjali, 2011; Cassidy \& Berlin, 1994); Unpredictability of the caregivers may increase anxiety.

Ambivalent attachment is a great risk factor for some symptoms of social anxiety compared to secure or avoidant attachment, as the only pattern related in the same direction with dimensions of the social anxiety. In other words, earlier ambivalent behavior toward caregiver may end in future fear of negative appraising, probably because ambivalent attachment children are less likely to explorate peer relationships. Furthermore, there is a positive association between concurrent ambivalent attachment and children's anxiety in unfamiliar and general situations (Bosquet \& Egeland, 2006). A wealth of evidence indicates that people with ambivalent attachment style have difficult and distressed behaviors and are more socially inhibited than secure or avoidant people (Cassidy \& Berlin, 1994).

People with avoidant attachment style do not show overt distraction when the attachment figure is not accessible and instead use a heightening self-confidence strategy (Main $\&$ Solomon, 1986) as a result of repeatedly rejection experienced when avoidant people seek to support from attachment figures. Avoidant people inability to use the attachment figure to cope with negative emotions may cause them to experience anxiety (Brumariu \& Kerns, 2008).

People with higher social anxiety, experience an exaggerated feeling of risk in social interactions. This risk is managed primarily through hypervigilance to signs of negative evaluation and avoidance of distressing emotions and thoughts (Aframn \& Kashdan, 2015). According to Kashdan, Volkmann, Breen, \& Han (2007), people with social anxiety tend to suppress their feelings in order to prevent the possible expression of unfavorable emotions to others which may invite social blunders, shame, and rejection. Social anxious people can be expected to fear the negative outcomes of expression of negative feelings such as anxiety and anger toward others. After all, expressing negative emotional reactions may lead individuals to view them as unlikely or vulnerable, which in turn, may be troublesome for their relationships (Öztürk \& Mutlu, 2010).
Also, it is assumed that attachment theory is one of the strongest theories that has deep connection with coping. Attachment is significantly able to predict vulnerability or resilience in the face of stressful events (Ghahvehchi, Fathi-Ashtiani, \& Azadfallah, 2012). Accordingly, attachment theory is able to account for individual differences in emotion regulation and how to manage stressful events (Mikulincer \& Nachshon, 1991) and process information (Zuroff \& Fitzpatrick, 1995). Research indicates that individuals with more secure attachments are better at regulating their emotions, constructing coping strategies such as problem solving, and seeking support from others, compared to less secure individuals (Cassidy \& Berlin, 1994).

In the light of these ideas, it seems logical to investigate the role of coping styles and attachment styles in the incidence of social anxiety. Since social anxiety is associated with negative cognitive, behavioral, and social-emotional consequences, it is necessary to understand factors that cause the incidence and maintenance of social anxiety. There is little evidence on the relationship between coping and attachment with social anxiety, so the present study is among the first to examine the relations of coping styles and attachment styles to social anxiety in Iran. Therefore, the current study aimed to investigate the relationship of coping styles and attachment styles with social anxiety.

\section{Methods}

The present study was a cross sectional research. Study population comprised all male and female students of Kashan high schools. A total of 440 students (196 males and 244 females, aged from 17 to 18 years) studying in the third or forth grade of Kashan City high schools (academic year 2015-2016) were selected by cluster sampling method. First, six girl and five boy schools were randomly selected. Then, two classes were selected from each school. Data were collected using social phobia inventory, coping inventory for stressful situation and adult attachment inventory. For analyzing the data, analysis of regression method was used. Written informed consents were obtained from the subjects. Peoples who agreed to participate in the study were asked to complete the questionnaires. Also, the objectives of the study were fully explained to the participants.

Social phobia inventory (SPIN) is a 17-item self-report measure designed to assess severity of social phobia. Items are measured 3 symptom dimensions on a 5-point Likerttype scale: fear with 6 items, avoidance with 7 items, and physiologic arousal with 4 items. This measure has excellent psychometric properties (Connor et al., 2000). Connor et al (2000) reported its Cronbach $\alpha$ as 0.94. The Cronbach alpha coefficients of subscales are as follows: fear, 0.89 ; 
avoidance, 0.81; and physiologic arousal, 0.80. Rezaei Dogaheh (2013) reported suitable internal consistency (Cronbach $\alpha=0.66$ and 0.87 for clinical and non-clinical group, respectively). Babaei et al. (2014) reported $\alpha$ value as 0.92. Hasanvand Amouzadeh et al. (2013) reported reliability coefficient of the test as 0.91 in Iranian population. Reliability coefficient of the subscales are as follows: fear, 0.75; avoidance, 0.74; and physiologic arousal, 0.75.

Endler and Parker (1990) designed coping inventory for stressful situation for evaluation of coping skills. This questionnaire comprised 48 items. The self-report items are presented in a Likert-type format, where participants rate items on a scale ranging from $1=$ never to $5=$ extreme. They reported reliability coefficients of 0.90 for problemfocuced coping style, 0.85 for emotion-focuced coping style, and 0.82 for avoidant coping style. In Michaeli Manee (2010) study, the Cronbach $\alpha$ was reported as 0.64 for problem-focuced coping style, 0.60 for emotion-focuced coping style, and 0.61 for avoidant coping style.

The adult attachment inventory instrument was used for measuring attachment styles. This scale was designed by Hazan and Shaver (1987). It is a 15-question test and measures 3 attachment styles of secure, avoidant, and ambivalent. A 5-point Likert-type scale (score of 1 for very low to 5 for very high) rates the answers. Cronbach $\alpha$ was calculated for all subscales questions of secure, avoidant, and ambivalent in a student sample (1480 students, including 860 girls and 620 boys). Its values were $0.86,0.84,0.85$ for 3 subscales of secure, avoidant, and ambivalent styles, respectively regarding all students. Whereas, for female students, the values were $0.86,0.83,0.84$ for 3 subscales of secure, avoidant, and ambivalent styles, respectively and for male students 0.84 , $0.85,0.86$ for 3 subscales of secure, avoidant, and ambivalent styles, respectively indicating good internal consistency of adult attachment scale (Besharat, 2011).

\section{Results}

To investigate the relationship between the coping styles and attachment styles with social anxiety, Pearson's correlations were computed. In order to determine the contributions of coping styles and attachment styles in the prediction of social anxiety, a stepwise multiple regression analysis was carried out. The predictors in the analysis were coping styles and attachment styles and the predicted variable was the social anxiety. Results of the descriptive statistics (Mean and standard deviation) for all variables are presented in Table 1. In Table 2, Pearson's correlations of variables are presented. There were correlations between the social anxiety with problem-focused coping style $(\mathrm{r}=-$ $0.16, \mathrm{P}<0.05)$, emotion-focused coping style $(\mathrm{r}=0.40$, $\mathrm{P}<0.01)$, and avoidance coping style $(\mathrm{r}=0.03$, N.S $)$.

Moreover, results showed correlation between social anxiety with secure attachment style $(\mathrm{r}=-0.10, \mathrm{P}<0.05)$, avoidant attachment style $(\mathrm{r}=0.23, \mathrm{P}<0.01)$, and ambivalent attachment style $(\mathrm{r}=0.26, \mathrm{P}<0.01)$. Results of the regression analyses are observed in Tables 3 and 4 . Based on the results, coping styles (emotion-focused and problem-focused styles) predicted $19 \%$ variation of social anxiety and at tachment styles predicted $11 \%$ variation of social anxiety.

\section{Discussion}

Social Anxiety Disorder (SAD) is characterized by fear of social situations as well as embarrassment or humiliation in social situations (Parade et al., 2009). The present

Table 1. Mean and standard deviation of social anxiety, coping styles, and attachment styles

\begin{tabular}{|c|c|c|c|c|c|c|c|c|}
\hline Variable & Frequency & Mean & SD & Minimum & Maximum & Low & $\begin{array}{c}\text { Limit } \\
\text { Average }\end{array}$ & High \\
\hline Social anxiety & 440 & 16.78 & 9.30 & 0 & 53 & $\begin{array}{c}260 \\
59.1 \%\end{array}$ & $\begin{array}{l}163 \\
37 \%\end{array}$ & $\begin{array}{c}17 \\
3.9 \%\end{array}$ \\
\hline Problem-focused coping style & 440 & 54.42 & 9.46 & 21 & 79 & $\begin{array}{c}32 \\
7.3 \%\end{array}$ & $\begin{array}{c}290 \\
65.9 \%\end{array}$ & $\begin{array}{c}118 \\
26.8 \%\end{array}$ \\
\hline Emotion-focused coping style & 440 & 46.45 & 10.18 & 18 & 47 & $\begin{array}{c}72 \\
16.4 \%\end{array}$ & $\begin{array}{c}284 \\
64.5 \%\end{array}$ & $\begin{array}{c}84 \\
19.1 \%\end{array}$ \\
\hline Avoidant coping style & 440 & 45.07 & 9.12 & 16 & 73 & $\begin{array}{c}54 \\
12.3 \%\end{array}$ & $\begin{array}{c}318 \\
72.3 \%\end{array}$ & $\begin{array}{c}68 \\
15.5 \%\end{array}$ \\
\hline Secure attachment & 440 & 15.99 & 3.32 & 6 & 25 & $\begin{array}{c}61 \\
13.9 \%\end{array}$ & $\begin{array}{l}321 \\
73 \%\end{array}$ & $\begin{array}{c}58 \\
13.2 \%\end{array}$ \\
\hline Avoidant attachment & 440 & 13.83 & 3.70 & 5 & 25 & $\begin{array}{c}115 \\
26.1 \%\end{array}$ & $\begin{array}{c}278 \\
63.2 \%\end{array}$ & $\begin{array}{c}47 \\
120.7 \%\end{array}$ \\
\hline Ambivalent attachment & 440 & 13.81 & 3.95 & 5 & 24 & $\begin{array}{c}140 \\
31.8 \%\end{array}$ & $\begin{array}{c}237 \\
53.9 \%\end{array}$ & $\begin{array}{c}63 \\
14.3 \%\end{array}$ \\
\hline
\end{tabular}


Table 2. Correlations among social anxiety, coping styles, and attachment styles

\begin{tabular}{|c|c|c|c|c|c|c|c|c|}
\hline Step & Variable & 1 & 2 & 3 & 4 & 5 & 6 & 7 \\
\hline 1 & Social anxiety & 1 & & & & & & \\
\hline 2 & Problem-focused coping style & $-0.16^{*}$ & 1 & & & & & \\
\hline 3 & Emotion-focused coping style & $0.40 * *$ & 0.03 & 1 & & & & \\
\hline 4 & Avoidant coping style & -0.03 & $0.37 * *$ & $0.15^{*}$ & 1 & & & \\
\hline 5 & Secure attachment & $-0.10^{*}$ & $0.12 *$ & $-0.10^{*}$ & $0.21 * *$ & 1 & & \\
\hline 6 & Avoidant attachment & $0.23 * *$ & -0.08 & $0.14^{*}$ & -0.05 & 0.09 & 1 & \\
\hline 7 & Ambivalent attachment & $0.26^{* *}$ & $-0.15^{*}$ & $0.23 * *$ & $0.13^{*}$ & $0.19 * *$ & 0.08 & 1 \\
\hline
\end{tabular}

$* * \mathrm{P}<0.01 . * \mathrm{P}<0.05$

PRACTIE in
CLINICAL PSYCH $Q$ LOGY

Table 3. Regression analyses of coping styles with regard to social anxiety

\begin{tabular}{|c|c|c|c|c|c|c|c|c|c|}
\hline Step & Predictor Variable & $\beta$ & B & $\mathbf{t}$ & $\mathbf{R}$ & $\mathbf{R}^{2}$ & $\begin{array}{l}\text { Adjusted } \\
\mathbf{R}^{2}\end{array}$ & $\begin{array}{c}\mathbf{R}^{2} \\
\text { Change }\end{array}$ & $\mathbf{P}$ \\
\hline \multirow{2}{*}{1} & $\begin{array}{l}\text { Emotion-focused cop- } \\
\text { ing style }\end{array}$ & 0.37 & 0.40 & 9.30 & \multirow{2}{*}{0.40} & \multirow{2}{*}{0.16} & \multirow[t]{2}{*}{0.16} & \multirow{2}{*}{0.16} & $<0.000$ \\
\hline & Constant & -0.52 & & -0.27 & & & & & $<0.05$ \\
\hline \multirow{3}{*}{2} & $\begin{array}{l}\text { Emotion-focused cop- } \\
\text { ing style }\end{array}$ & 0.37 & 0.41 & 9.59 & \multirow{3}{*}{0.44} & \multirow{3}{*}{0.19} & \multirow{3}{*}{0.19} & \multirow{3}{*}{0.03} & $<0.000$ \\
\hline & $\begin{array}{l}\text { Problem-focused cop- } \\
\text { ing style }\end{array}$ & -0.17 & -0.17 & -4.06 & & & & & $<0.000$ \\
\hline & Constant & 8.57 & & 2.93 & & & & & $<0.000$ \\
\hline
\end{tabular}

PRACTICE in CLINICAL PSYH $Q$ LOGY

study aimed to investigate the relationship of coping styles and attachment styles with social anxiety among students. Our study results showed significant relationship between coping styles and social anxiety. This finding is consistent with the results of earlier research (Doron et al., 2013; Salajegheh \& Bakhshani, 2014; Razavi, Kazemi, \& Mon hammadi, 2011). Evidently, the theoretical model of social anxiety has emphasized the impairments in interpersonal skills. Accordingly, lack of interpersonal skills to handle threatening situations leads to social anxiety (Vitasari, Wahab, Herawan, \& Sinnadurai, 2011). Coping skill is one of the interpersonal skills and part of the efforts to protect the person in stressful situations. In this regard, some coping

Table 4. Regression analyses of attachment styles with regard to social anxiety

\begin{tabular}{|c|c|c|c|c|c|c|c|c|c|}
\hline Step & Predictor Variable & $\beta$ & B & $t$ & $\mathbf{R}$ & $\mathbf{R}^{2}$ & $\begin{array}{c}\text { Adjusted } \\
\mathbf{R}^{2}\end{array}$ & $\begin{array}{c}\mathbf{R}^{2} \\
\text { Change }\end{array}$ & $\mathbf{P}$ \\
\hline \multirow{2}{*}{1} & Ambivalent attachment & 0.63 & 0.26 & 5.17 & \multirow{2}{*}{0.26} & \multirow{2}{*}{0.07} & \multirow{2}{*}{0.07} & \multirow{2}{*}{0.07} & $<0.000$ \\
\hline & Constant & 8.05 & & 5.17 & & & & & $<0.000$ \\
\hline \multirow{3}{*}{2} & Ambivalent attachment & 0.54 & 0.23 & 5.04 & \multirow{3}{*}{0.32} & \multirow{3}{*}{0.10} & \multirow{3}{*}{0.10} & \multirow{3}{*}{0.03} & $<0.000$ \\
\hline & Avoidant attachment & 0.47 & 0.18 & 4.08 & & & & & $<0.000$ \\
\hline & Constant & 2.68 & & 1.31 & & & & & $<0.05$ \\
\hline \multirow{4}{*}{3} & Ambivalent attachment & 0.57 & 0.24 & 5.27 & \multirow{4}{*}{0.34} & \multirow{4}{*}{0.11} & \multirow{4}{*}{0.11} & \multirow{4}{*}{0.01} & $<0.000$ \\
\hline & Avoidant attachment & 0.44 & 0.17 & 3.81 & & & & & $<0.000$ \\
\hline & Secure attachment & -0.28 & -0.10 & -2.26 & & & & & $<0.05$ \\
\hline & Constant & 7.38 & & 2.56 & & & & & $<0.05$ \\
\hline
\end{tabular}


skills as cognitive and behavioral efforts to meet internal and external needs have been introduced (Eksi, 2004).

Our study results supported a negative relationship between problem-focused coping style and social anxiety. Carver, Scheier, and Weintraub (1989) believed since in coping strategies, target behavior is control or change of sources of stress, strategies such as planning and devising a plan of action and new techniques to be used, so anxiety is reduced to the situation. In other words, people using problem-focused coping strategies actually experience problem and thereby reduce concerns. Training of problem-focused coping skills can reduce anxiety and stress (Emamipur, 2011).

Furthermore, this study demonstrated that emotion-focused coping style was positively correlated with social anxiety. Presumably, emotion-focused coping style include strategies that reduce emotional distress and expression of feelings and prevent taking appropriate actions in stressful situations (Struthers et al., 1995). This style does not alleviate anxiety, but may even exaggerate it. Keough et al. findings (2015) indicated that people with high social anxiety use emotion-focused coping style to reduce their anxiety. Apparently, people with anxiety disorders compared to normal people are more likely to think about their feelings about negative events and less concerned how to control those events (Legerstee, Garnefski, Jellesma, Verhulst, \& Utens, 2009).

Another finding of the present study showed that secure attachment has a negative relationship with social anxiety that is in line with previous findings (Hasani, Sheikhan, Aryanakia, \& Mahmoudzadeh, 2013; Parade, et al., 2009; Brumariu $\&$ Kerns, 2008). It seems that people with secure attachment have higher self-esteem, interpersonal trust and intimacy which leads to healthier relationships. In addition, their higher self-efficacy and more impact on the social situations make them more able to initiate, maintain, and sustain interpersonal relationships (Goodwin, 2010; Cited in Rashidipour, 2012).

Our study indicated a positive relationship between avoidant attachment style and social anxiety. People who show higher levels of avoidant attachment in a new situation, report less social anxiety. It seems that avoidance can help adjustment function in some situations. When people avoid their tension but also the desire to suppress it and thus, denial of anxiety, it may keep the attachment system deactivated. In this way, people with avoidant attachment, probably have less social anxiety in social situations and do not need to show intimacy. But this type of attachment causes difficulty in establishing intimate friendships or romantic relationships, and when more intimacy is needed, it can develop social anxiety (Brumariu \& Kerns, 2008).
This study also showed that social anxiety had a positive relationship with ambivalent attachment. This finding is consistent with research findings of Hasani et al. (2013), Besharat et al. (2012). Carver, Scheier, and Weintraub (1989) believe that by using problem solving strategies, individual is in control sources of stress and by planning and devising, the anxiety is reduced. It makes suspicious person in social situations confusion, restlessness, fear and anxiety and anxiety disorders in her or his ultimately be provided (Tasca et al., 2009). The initial ambivalent behavior towards the mother increase the fear of negative evaluation. Consequently, ambivalent people may have less opportunity to discover the peer relationships (Brumariu \& Kerns, 2008). Based on evidence, ambivalent people more than avoidance-immune individuals are problematic, distressed, and socially abnormal (Cassidy \& Berlin, 1994; quoted in Brumariu \& Kerns, 2008).

People with insecure attachments doubt their attachment figures as a secure perch to help them decrease distress. Frequent daily experiences with attachment figures and the consequences of ambivalent and avoidant patterns of attachment may explain how people interact in social situations as well as the expectations and emotions they have in social interactions (Brumariu \& Kerns, 2008).

Since the current study investigated the role of coping styles and attachment styles in social anxiety in general population, it is difficult to generalize its results to clinical population. Using self-report questionnaire is another limitation of the present study. It may be of benefit to conduct research where coping styles and attachment styles of youth with social anxiety are evaluated compared to youth with other anxiety disorders and non-clinical samples.

Findings of the current study have direct implications for case understanding, therapeutic processes, and prevention programs when working with people with social anxiety. Further intervention studies must be conducted to assess the efficiency of improving coping styles and security in communications to alleviate social anxiety. Thus, intervention studies could reveal whether coping styles and attachment patterns contribute in the development and maintenance of social anxiety.

\section{Acknowledgments}

This paper had no financial supporters. We appreciate the high schools students and principals for contributing to this research.

\section{Conflict of Interest}

The author declared no conflicts of interest. 


\section{References}

Afram, A., \& Kashdan, T. B. (2015). Coping with rejection concerns in romantic relationships: An experimental investigation of social anxiety and risk regulation. Journal of Contextual Behavioral Science, 4(3), 151-156. doi: 10.1016/j.jcbs.2015.04.003

Alkozei, A., Creswell, C., Cooper, P. J., \& Allen, J. J. B. (2015). Autonomic arousal in childhood anxiety disorders: Associations with state anxiety and social anxiety disorder. Journal of Affective Disorders, 175, 25-33. doi: 10.1016/j.jad.2014.11.056

American Psychiatric Association (2013). Diagnostic and statistical manual of mental disorders. ( $5^{\text {th }}$ Ed.). Washington, D.C.: American Psychiatric Association.

Armsden, G. C., \& Greenberg, M. T. (1987). The inventory of parent and peer attachment: Individual differences and their relationship to psychological well-being in adolescence. Journal of Youth and Adolescence, 16(5), 427-454. doi: 10.1007/bf02202939

Babaei, Z., Pourshahbaz, A., Rezaei Dogaheh, E., \& Dolatshahi, B. (2014). The relationship between negative and positive affectivity, self-focused attention and attentional control with severity of social anxiety symptoms. Practice in Clinical Psychology, 2(3), 149-154.

Beesdo-Baum, K., Knappe, S., Fehm, L., Höfler, M., Lieb, R Hofmann, S. G., et al. (2012). The natural course of social anxiety disorder among adolescents and young adults. Acto Psychiatrica Scandinavica, 126(6), 411-425. doi: 10.1111/j.16000447.2012.01886.x

Besharat, M. A. (2011). Development and Validation of Adult Attachment Inventory. Procedia - Social and Behavioral Sciences, 30 475-479. doi: 10.1016/j.sbspro.2011.10.093

Besharat, M. A. (2012). [The mediating role of defence mechanisms in the relationship between attachment style and alexithymia (Persian)]. Journal of Applied Psychology, 6(1), 7-22.

Besharat, M. A., Mohammadi Hasel, K., Nikfarjam, M. R., Zabihzadeh, A., Fallah, M. H. (2012). A comparison of attachment styles in individuals with depression, anxiety disorders, and those without these disorders. Developmental Psychology: Iranian Psychologists, 9(35), 227-236.

Bowlby, J. (1973). Attachment and loss,separation: Anxiety and anger. New York: Basic Books.

Brumariu, L. E., \& Kerns, K. A. (2008). Mother-child attachment and social anxiety symptoms in middle childhood. Journal of Applied Developmental Psychology, 29(5), 393-402. doi: 10.1016/j. appdev.2008.06.002

Bosquet, M., \& Egeland, B. (2006). The development and maintenance of anxiety symptoms from infancy through adolescence in a longitudinal sample. Development and Psychopathology, 18(2), 517-50. doi:10.1017/s0954579406060275

Carver, C. S., Scheier, M. F., \& Weintraub, J. K. (1989). Assessing coping strategies: A theoretically based approach. Journal of Personality and Social Psychology, 56(2), 267-83. doi: 10.1037/00223514.56.2.267

Cassidy, J., \& Berlin, L. J. (1994). The insecure/ambivalent pattern of attachment: Theory and research. Child Development, 65(4), 971-7. doi: $10.2307 / 1131298$

Connor, K. M., Davidson, J. R. T., Churchill, L. E., Sherwood, A., Foa, E., \& Wesler, R. H. (2000). Psychometric properties of the
Social Phobia Inventory (SPIN): New self-rating scale. The British Journal of Psychiatry, 176(4), 379-386. doi: 10.1192/bjp.176.4.379

Coyne, G. (2003). An investigation of coping skills and quality of life among single sole supporting mothers. International Journal of Anthropology, 18(3), 127-138. doi: 10.1007/bf02447541

Doron, J., Thomas-Ollivier, V., Vachon, H., \& Fortes-Bourbousson, M. (2013). Relationships between cognitive coping, self-esteem, anxiety and depression: A cluster-analysis approach. Personality and Individual Differences, 55(5), 515-520. doi: 10.1016/j. paid.2013.04.017

Eksi, H. (2004). Personality and coping: A multidimensional research on situational and dispositional coping. Educational Sciences: Theory \& Practice, 4(1), 94-98.

Emamipur, S. (2011). [The effectiveness of progressive relaxation training and coping skills, problem-solving on socially damaged women and girls (Persian)]. Tehran: Islamic Azad University, Central Branch.

Endler, N. S., \& Parker, J. D. (1990). Multidimensional assessment of coping: A critical evaluation. Journal of Personality and Social Psychology, 58(5), 844-854. doi: 10.1037/0022-3514.58.5.844

Faramarzi, M., Pasha, H., Esmaelzadeh, S., Jorsarai, G., Mir, M. R A., \& Abedi, S. (2013). Is coping strategies predictor of anxiety and depression in couple infertile? Health, 5(3), 643-649. doi: 10.4236/health.2013.53a085

Finnegan, R. A., Hodges, E. V. E., \& Perry, D. G. (1996). Preoccupied and avoidant coping during middle childhood. Child Development, 67(4), 1318. doi: 10.2307/1131702

Garcia-Lopez, L. J., Díaz-Castela, M. M., Muela-Martinez, J. A., \& Espinosa-Fernandez, L. (2014). Can parent training for parents with high levels of expressed emotion have a positive effect on their child's social anxiety improvement? Journal of Anxiety Dis orders, 28(8), 812-822. doi: 10.1016/j.janxdis.2014.09.001

Ghahvehchi, F., Fathi Ashtiani, A., \& Azad Fallah, P. (2012). [The relationship between meta cognitive beliefs and students' test anxiety coping styles, given the role of ambivalent attachment (Persian)]. Research in Psychological Health, 6(3), 12-18.

Ghassem Boroujerdi, F., Sohrabi, F., \& Borjali, A. (2011). [Evaluation of the interactive relationship between attachment styles, coping styles and mental health in adolescents (Persian)]. Journal of Social Psychology, 7(21), 85-100.

Greco, L. A., \& Morris, T. L. (2005). Factors influencing the link between social anxiety and peer acceptance: Contributions of social skills and close friendships during middle childhood. Behavior Therapy, 36(2), 197-205. doi: 10.1016/s0005-7894(05)80068-1.

Hasani, J., Sheikhan, R., Aryanakia, E., \& Mahmoudzadeh, A. (2013). [Adolescents social anxiety: Role of attachment style and cognitive emotion regulation strategies (Persian)]. Developmental Psychology, 9(36), 363-76.

Hassanvand Amouzadeh, M., Roshan Chesly, R., \& Hassanvand Amouzadeh, M. (2013). [The relationship of the meta-cognitive beliefs with social anxiety symptoms (avoidance, fear and physiological arousal) in non-clinical population (Persian)]. Behavioural and Cognitive Sciences Research, 2(5), 55-70

Hazan, C., \& Shaver, P. (1987). Romantic love conceptualized as an attachment process. Journal of Personality and Social Psychology, 52(3), 511-524. doi: 10.1037/0022-3514.52.3.511 
Herbert, J. D., Gaudiano, B. A., Rheingold, A. A., Myers, V. H., Dalrymple, K., \& Nolan, E. M. (2005). Social skills training augments the effectiveness of cognitive behavioral group therapy for social anxiety disorder. Behavior Therapy, 36(2), 125-138. doi: 10.1016/s0005-7894(05)80061-9

Kashdan, T. B., Farmer, A. S., Adams, L. M., Ferssizidis, P., McKnight, P. E., \& Nezlek, J. B. (2013). Distinguishing healthy adults from people with social anxiety disorder: Evidence for the value of experiential avoidance and positive emotions in everyday social interactions. Journal of Abnormal Psychology, 122(3), 645-655. doi: $10.1037 / \mathrm{a} 0032733$

Kashdan, T. B., Volkmann, J. R., Breen, W. E., \& Han, S. (2007). Social anxiety and romantic relationships: The costs and benefits of negative emotion expression are context-dependent. Journal of Anxiety Disorders, 21(4), 475-92. doi: 10.1016/j. janxdis.2006.08.007

Lazarus, R. S. \& Folkman, S. (1984). Stress, appraisal, and coping. New York: Springer.

Lechner, L., Bolman, C., \& van Dalen, A. (2006). Definite involuntary childlessness: associations between coping, social support and psychological distress. Human Reproduction, 22(1), 288-294. doi: 10.1093/humrep/del327

Legerstee, J. S., Garnefski, N., Jellesma, F. C., Verhulst, F. C., \& Utens, E. M. W. J. (2009). Cognitive coping and childhood anxiety disorders. European Child \& Adolescent Psychiatry, 19(2), 143150. doi: $10.1007 /$ s00787-009-0051-6

Liveneh, W., Sheldon, M., \& Kaplan, J. (1991) The relationship between anxiety and coping modes. Journal of Human Behaviour, 36(3), 1369-9.

Main, M., \& Solomon, J. (1986). Discovery of a new, insecure-disorganized/disoriented attachment pattern. In T. B. Brazelton, \& M. V. Yogman (Eds.). Affective Development in Infancy (pp. 95-124). Norwood, N.J.: Ablex.

Michaeli Manee F. (2010). [The role of coping with stress styles between irrational beliefs and social adjustment relationship among Urmia university students (Persain)]. Research in Psychology Health, 3(4), 45-54.

Mikulincer, M., \& Nachshon, O. (1991). Attachment styles and patterns of self-disclosure. Journal of Personality and Social Psychology, 61(2), 321-331. doi: 10.1037/0022-3514.61.2.321

Mychailyszyn, M. P., Méndez, J. L., \& Kendall, P. C. (2010).School functioning in youth with and without anxiety disorders: Comparisons by diagnosis and comorbidity. School psycholog. 39(1), 106-121.

Öztürk, A., \& Mutlu, T. (2010). The relationship between attachment style, subjective well-being, happiness and social anxiety among university students. Procedia - Social and Behavioral Sciences, 9, 1772-1776. doi: 10.1016/j.sbspro.2010.12.398

Parade, S. H., Leerkes, E. M., \& Blankson, A. N. (2009). Attachment to parents, social anxiety, and close relationships of female students over the transition to college. Journal of Youth and Adolescence, 39(2), 127-137. doi: 10.1007/s10964-009-9396-x

Ranta, K., Kaltiala-Heino, R., Fröjd, S., \& Marttunen, M. (2012). Peer victimization and social phobia: A follow-up study among adolescents. Social Psychiatry and Psychiatric Epidemiology, 48(4), 533-544. doi: 10.1007/s00127-012-0583-9
Rashidipour, P. (2012). [The relationship between attachment style and body image students with social anxiety of Tehran high school girls (Persian)] [MA thesis]. Tehran: University of Allameh Tabatabai.

Razavi, A., Kazemi, S., \& Mohammadi, M. (2011). Investigate the relationship between personality traits and coping with social anxiety of blind and normal students of the universities of Fars (Persian)]. Quarterly Psychology Of Exceptional Individuals, 1(4), 109-133.

Rezaei Dogaheh, E. (2013). Psychometric properties of Farsi version of the Social Phobia Inventory (SPIN). Procedia - Social and Behavioral Sciences, 84, 763-768. doi: 10.1016/j.sbspro.2013.06.642

Salajegheh, S \& Bakhshani, N. (2014). [Effectiveness of combined group exposure therapy and coping with stress skills training on social anxiety rate of university students (Persian)]. Knowledge and Research in Applied Psychology, 15(56), 96-104.

Struthers, C. W., Perry, R. P., Menec, V. H., Schonwetter, D. J., Hechter, F. J., Winberg, L., et al. (1995). Assessing dispositional coping strategies in college students: A domain-specific measure. Paper presented at the Annual Meeting of the American Educational Research Association, San Francisco, USA, 18-22 April 1995.

Suveg, C., \& Zeman, J. (2004). Emotion regulation in children with anxiety disorders. Journal of Clinical Child \& Adolescent Psychology, 33(4), 750-759. doi: 10.1207/s15374424jccp3304_10

Tasca, G. A., Szadkowski, L., Illing, V., Trinneer, A., Grenon, R., Demidenko, N., et al. (2009). Adult attachment, depression, and eating disorder symptoms: The mediating role of affect regulation strategies. Personality and Individual Differences, 47(6), 662667. doi: 10.1016/j.paid.2009.06.006

Vertue, F. M. (2003). From adaptive emotion to dysfunction: an attachment perspective on social anxiety disorder. Personality and Social Psychology Review, 7(2), 170-191. doi: 10.1207/ s15327957pspr0702_170-191

Vitasari, P., Wahab, M. N. A., Herawan, T., \& Sinnadurai, S. K. (2011). Representation of social anxiety among engineering students. Procedia - Social and Behavioral Sciences, 30, 620-624. doi: 10.1016/j.sbspro.2011.10.120

Zuroff, D. C., \& Fitzpatrick, D. K. (1995). Depressive personality styles: Implications for adult attachment. Personality and Individual Differences, 18(2), 253-265. doi: 10.1016/0191-8869(94)00136-g 